\title{
Effect of treatment using silane coupling agent on creep properties of jute fiber reinforced composites
}

\author{
K. Takemura, Y. Takada \& H. Katogi \\ Department of Mechanical Engineering, Kanagawa University, Japan
}

\begin{abstract}
In this study, effects of surface treatment on tensile and flexural creep properties of jute fiber reinforced composite were investigated. The reinforcement was plain woven jute fiber cloth and matrix was polylactic acid (PLA). The jute fiber cloth and PLA are naturally-derived materials. So, the jute fiber reinforced composites have a poor interfacial adhesion. Therefore, the silane coupling agent treatment was used to improve the interfacial adhesion. The alkoxy group of silane is hydrolyzed and changed by silanol group ( $\mathrm{Si}-\mathrm{OH})$. And interface adhesion improvement is expected by covalent bond with the hydroxyl group of the jute fiber surface. As a result, the interfacial adhesion between jute fiber and matrix was improved by the silane treatment, and the tensile and flexural creep strains of composite decreased. The creep compliance of composite was improved by using silane treated jute fiber except for flexural creep compliance at high temperature.
\end{abstract}

Keywords: natural fiber, PLA, silane coupling agent, creep, surface treatment.

\section{Introduction}

Glass fiber reinforced plastics (GFRP) have high specific strength, stiffness and corrosion resistance. GFRP has been used for bathtub, marine applications and so on. GFRP has an environmental problem about waste disposal after use. However, GFRP generates $\mathrm{CO}_{2}$ at disposal processing. In order to solve this environmental problem, new composite materials were required instead of GFRP. Recently, the researches on natural fiber reinforced plastic (NFRP) that combines the natural fibers and biodegradable polymer were actively conducted $[1-4]$. 
NFRP is naturally-derived materials, but it has a poor interfacial adhesion. So, NFRP has low mechanical properties. Poor interfacial adhesion often leads to shortage of impregnation, interfacial deboning and poor interfacial adhesion affect the material strength.

As a solution to the problem, a variety of chemical methods [5] have been used for NFRP. Lee et al. [6] reported the effect of interfacial adhesion on tensile and flexural properties of polypropylene-bamboo composites. They treated the bamboo fiber with silane coupling agent. The tensile and flexural properties of composite using silane treated bamboo fiber were improved by the treatment for the high adhesion between fiber and matrix. Reid et al. [7] reported the effect of the interfacial adhesion on bending properties of polypropylene-kenaf composites. They treated the kenaf fiber with alkaline solution and silane coupling agent. The flexural property of the composite was improved by surface treatment. In spite of many reports on NFRP, there is a few report of the creep property for industrial application and long term safety.

In this study, effect of surface treatment on creep properties of jute fiber reinforced plastic was investigated.

\section{Specimen and testing method}

\subsection{Materials}

PLA sheet (TERAMAK SS300, Unitika Co.) was used as matrix. The reinforcement was plane woven jute fiber cloths (Kawashima Selkon). Young's modulus and the density for jute fiber were $26 \mathrm{GPa}$ and $1.44\left(\mathrm{~g} / \mathrm{cm}^{3}\right)$ respectively. The interfacial adhesion between fibers and matrix was modified using a silane coupling agent (Z-6040, TorayDow Corning Co.).

\subsection{Surface modification}

In order to improve interfacial adhesion of fiber and matrix, the jute fiber was modified by using silane coupling agent. Silane coupling agent treatment was carried out in distilled water with $5 \%$ silane coupling content for 1 hour at $25^{\circ} \mathrm{C}$. After that, the specimens are dried in the oven for 24 hours at $50^{\circ} \mathrm{C}$.

\subsection{Composites fabrication}

For composite fabrication, the plain woven jute fiber cloth was completely dried at $50^{\circ} \mathrm{C}$ in an oven. The fiber weight fraction of composite was $35 \mathrm{wt} \%$. The composite was fabricated by the compression molding method with vacuum using a heat press machine. Woven jute fiber cloths and PLA sheets were placed in an aluminum matched-die mold. The molding temperature was $190^{\circ} \mathrm{C}$, pressure was $1.3 \mathrm{MPa}$, and holding time was $10 \mathrm{~min}$. Then the mold was cooled down to room temperature (R.T.) by city running water. In this study, jute fiber reinforced composite is called as JFC, and silane coupling agent treated JFC is called as SJFC. 
The dimensions of the specimen of the tensile creep test was based on the Japanese Industrial Standards (JIS K 7115). Length was $250 \mathrm{~mm}$ or more, width was $15 \pm 0.5 \mathrm{~mm}$ and thickness was $3 \pm 0.2 \mathrm{~mm}$. The specimen of flexural creep test was based on JIS K 7116. Length was $80 \mathrm{~mm}$ or more, width was $10 \mathrm{~mm}$ and thickness was $4 \mathrm{~mm}$.

\subsection{Tensile and flexural creep test}

The tensile creep test was also referred to JIS K 7115. Creep tester 100LER (Toyo Seiki Seisaku-sho Co.) was used for testing machines. In the tensile creep test, the constant load was $300 \mathrm{~N}$ (it is about $10 \%$ of the tensile strength). The maximum test time was 100 hours, and environment temperatures were R.T., 40 and $60^{\circ} \mathrm{C}$.

\subsection{Flexural creep test}

The flexural creep test was also referred to JIS K 7116. Creep tester (ADVSNCE FS-620P) was used for testing machines. In the flexural creep test, the constant load was $40 \mathrm{~N}$ (it is about $25 \%$ of the bending strength). The maximum test time was 50 hours, and environment temperatures were R.T., 40 and $60^{\circ} \mathrm{C}$.

\section{Results and discussion}

\subsection{Tensile and flexural creep behavior}

Figure 1 shows tensile creep behavior of JFC and SJFC at R.T.. When initial strains of JFC and SJFC are compared, there is not much difference between

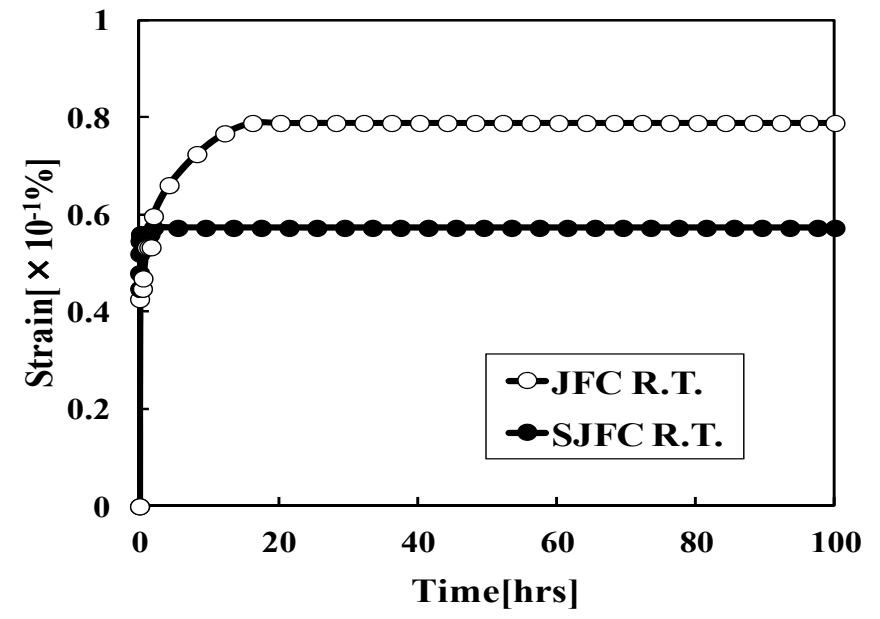

Figure 1: $\quad$ Tensile creep behavior of JFC and SJFC at R.T. 
them. However, it can be confirmed that the creep rates of JFC and SJFC decrease at 10 hours after the start of the test. The tensile creep strain of SJFC was approximately $30 \%$ lower than that of JFC. This behavior can be directly related with the interfacial adhesion. The alkoxy group of silane is hydrolyzed and changed silanol group ( $\mathrm{Si}-\mathrm{OH})$ [8]. The interfacial adhesion is improved by covalent bond with the hydroxyl group of jute fiber surface. It leads to the enhancement of creep behavior.

Figure 2 shows tensile creep behavior of JFC and SJFC at 40 and $60^{\circ} \mathrm{C}$. The creep strain decreases by silane treatment at each temperature. There is no significant difference in $40^{\circ} \mathrm{C}$ between JFC and SJFC. The tensile creep strain of SJFC was approximately $80 \%$ lower than that of JFC at $60^{\circ} \mathrm{C}$. The glass transition temperature of PLA used in this study is about $58^{\circ} \mathrm{C}$. The PLA was rapidly softened above the glass transition temperature. The stiffness of composite can be decreased. Therefore, tensile creep strain of JFC at $60^{\circ} \mathrm{C}$ became big. Nevertheless, the use of the silane coupling agent modification was noticeably reduced the creep strain at the $60^{\circ} \mathrm{C}$.

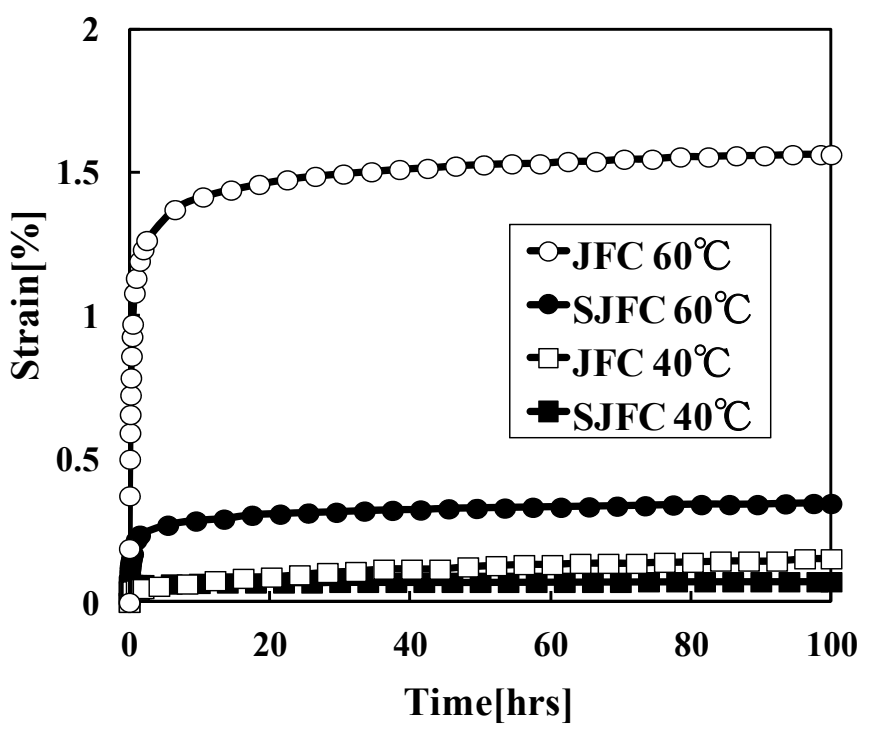

Figure 2: Tensile creep behavior of JFC and SJFC at $40,60^{\circ} \mathrm{C}$.

Figure 3 shows flexural creep behavior of JFC and SJFC at R.T. Figure 4 shows flexural creep behavior of JFC and SJFC at 40 and $60^{\circ} \mathrm{C}$. The flexural creep strain of SJFC was approximately $50 \%$ lower than that of JFC at R.T. This behavior can be directly related with the interfacial adhesion. The creep strain of SJFC was approximately $60 \%$ lower than that of JFC at $40^{\circ} \mathrm{C}$. Creep strains of $\mathrm{JFC}$ and $\mathrm{SJFC}$ at $60^{\circ} \mathrm{C}$ increased to failure due to glass transition temperature. 


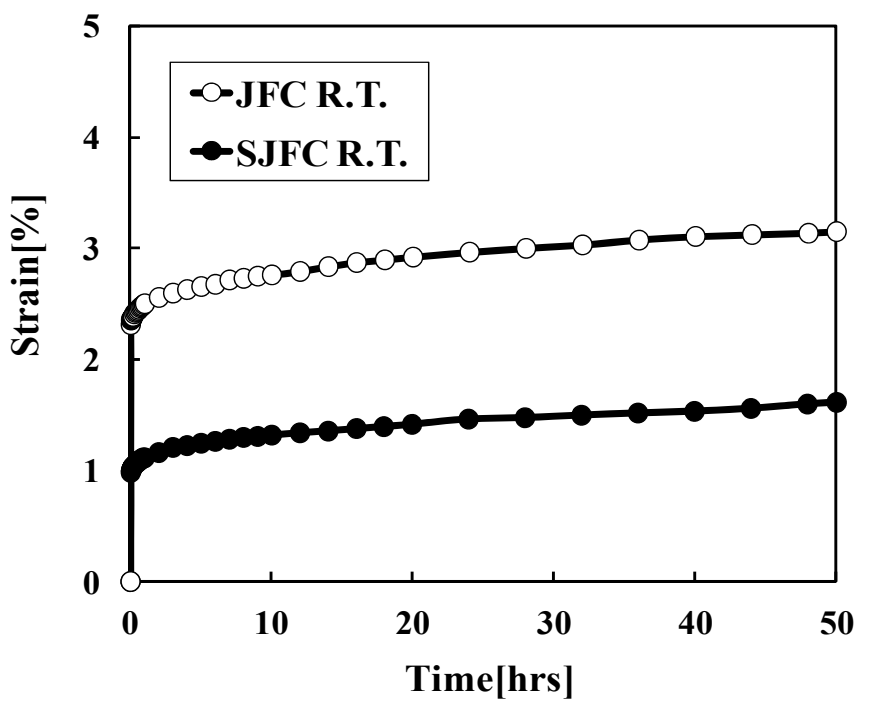

Figure 3: $\quad$ Flexural creep behavior of JFC and SJFC at R.T.

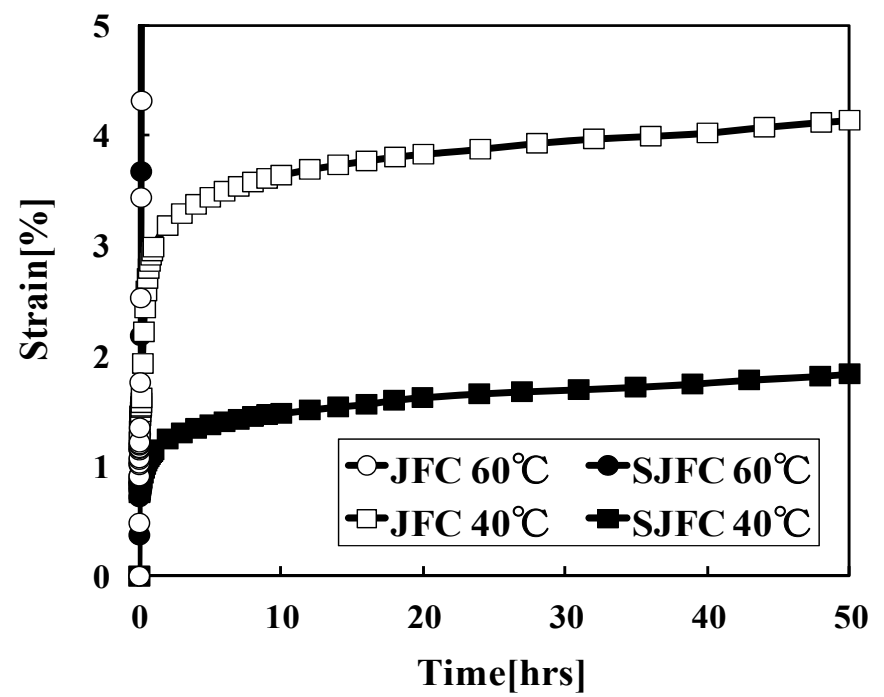

Figure 4: $\quad$ Flexural creep behavior of JFC and SJFC at $40,60^{\circ} \mathrm{C}$.

\subsection{Creep compliance}

Figure 5 shows relationship between creep compliances and time under three temperatures. In case of tensile and flexural creep tests under R.T. and $40^{\circ} \mathrm{C}$, creep compliances of SJFC were lower than those of JFC. In particular, tensile 


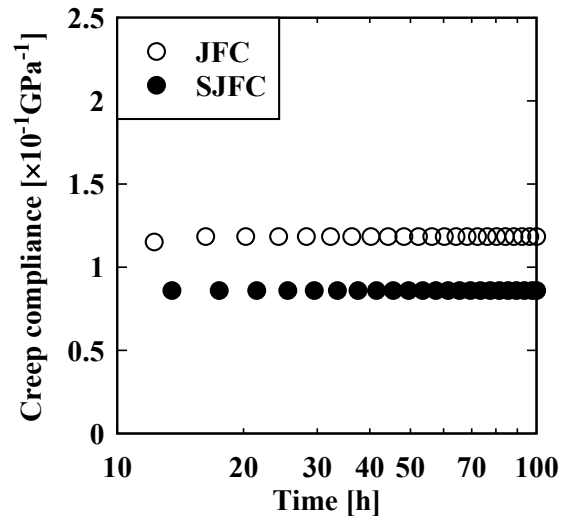

(a) Tensile test at R.T.

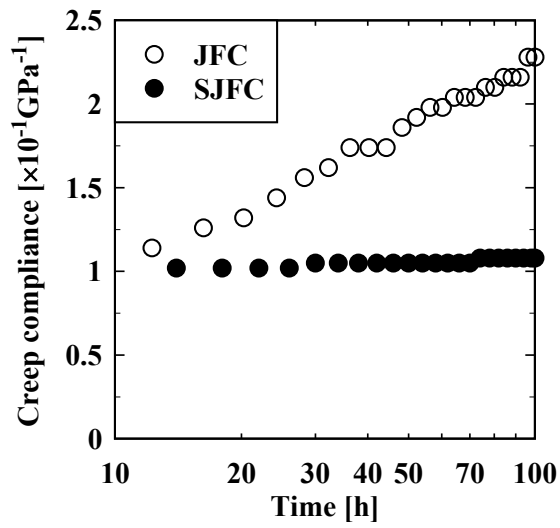

(c) Tensile test at $40^{\circ} \mathrm{C}$.

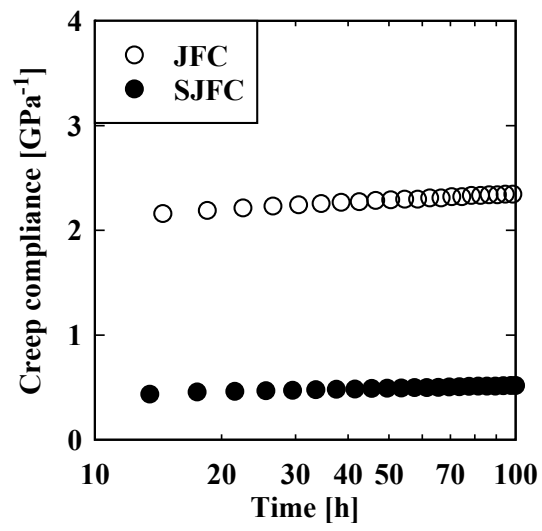

(e) Tensile test at $60^{\circ} \mathrm{C}$.

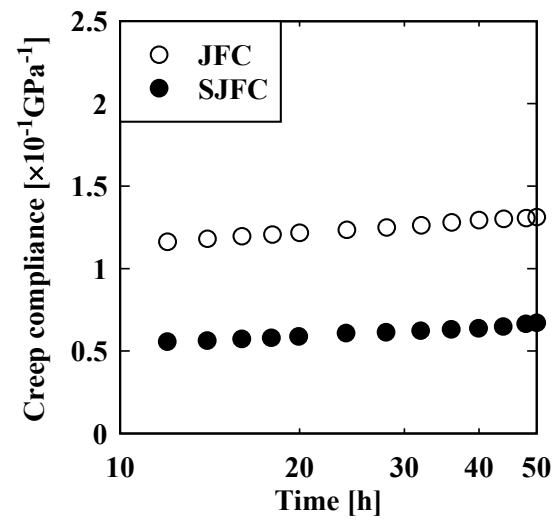

(b) Flexural test at R.T.

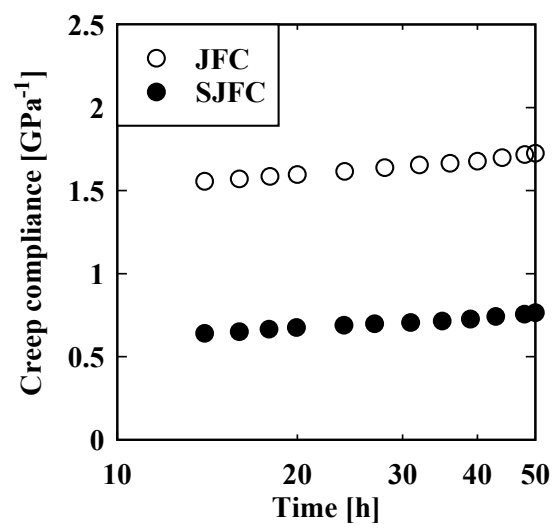

(d) Flexural test at $40^{\circ} \mathrm{C}$.

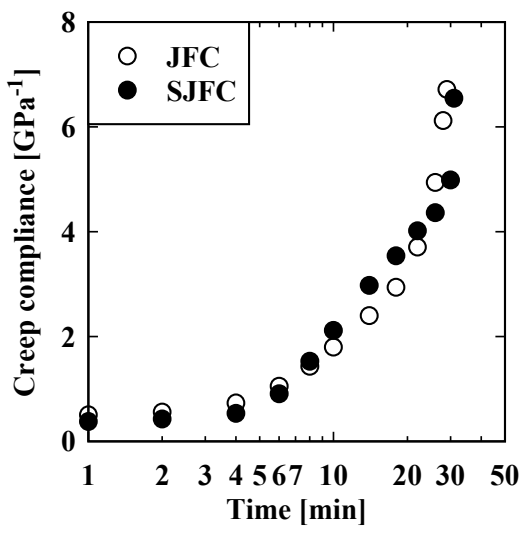

(f) Flexural test at $60^{\circ} \mathrm{C}$.

Figure 5: Relationship between creep compliance and time. 
creep compliance of SJFC at $60^{\circ} \mathrm{C}$ was noticeably lower than that of JFC at $60^{\circ} \mathrm{C}$. However, flexural creep compliance of SJFC at $60^{\circ} \mathrm{C}$ was similar to that of JGC at $60^{\circ} \mathrm{C}$. Their results implied that interfacial adhesion was affected by visco-elastic behavior of PLA. Therefore, tensile creep compliance of composite was improved by using silane treated jute fiber, and the flexural creep compliance strongly improved except for $60^{\circ} \mathrm{C}$.

\section{Conclusions}

In this study, effects of surface treatment on tensile and flexural creep properties of jute fiber reinforced composite were investigated. As a result, following conclusions were obtained.

(1) The interfacial adhesion between jute fiber and PLA was improved by the silane treatment. The tensile creep strain of composite using silane treatment decreased. The result implied that silanol group (Si-OH) was effective in covalent bond with hydroxyl group of fiber surface.

(2) In case of flexural creep test under R.T., 40 and $60^{\circ} \mathrm{C}$, the flexural creep strain of composite using silane treatment was approximately lower than that of virgin composite. The PLA as matrix was rapidly softened in high temperature above the glass transition temperature, and the flexural creep strain decreased. This behavior can be directly related with the interfacial adhesion.

(3) In case of tensile creep compliance under R.T. and $40^{\circ} \mathrm{C}$, tensile creep compliances of composites using silane treatment were lower than that of virgin composite. In particular, tensile creep compliance of composite using silane treatment under $60^{\circ} \mathrm{C}$ was noticeably lower than that of virgin composite. However, flexural creep compliance of composite using silane treatment at $60^{\circ} \mathrm{C}$ did not change.

\section{References}

[1] Rokbi, M., Osmani, H., Imad A. and Benseddiq, N., Effect of Chemical treatment on Flexure Properties of Natural Fiber-reinforced Polyester Composite, Noureddine Benseddiq Procedia Engineering, 10, pp. 20922097, 2011.

[2] Saha, P., Manna, S., Chowdhury, S.R., Sen, R., Roy, D., and Adhikan, B., Enhancement of tensile strength of lignocellulosic jute fibers by alkali-steam treatment, Bioresource Technology, 101(9), pp. 3182-3187, 2010.

[3] Dhakal H.N., Zhang Z.Y. and Richardson M.O.W., Creep Behaviour of Natural Fiber Reinforced Unsaturated Polyester Composites, Journal of Biobased Materials and Bioenergy, 3(3), pp. 232-237, 2009.

[4] Acha, B.A., Reboredo, M.M. and Marcovinch, N.E., Creep and dynamic mechanical behavior of PP-jute composites: Effect of the interfacial adhesion, Composites Applied Science and manufacturing, 38(6), pp. 15071516, 2007. 
[5] Tao, Y., Ren, J., Li, S., Yuan H. and Li, Y., Effect of fiber surfacetreatments on the properties of poly(lactic acid)/ramie composites, Composites Part A: Applied Science and Manufacturing, 41(4), pp. 499-505, 2010.

[6] Lee, S.Y., Chun, S.J. and Doh, G.H., Influence of Chemical Modification and Filler Loading on Fundamental Properties of Bamboo Fibers Reinforced Polypropylene Composites, Journal of Composite Materials, 43(15), pp. 1639-1657, 2009.

[7] Reid, R.G., Asumani, O. M. L. and Paskaramoorthy, R., The Effect on the Mechanical Properties of Kenaf Fibre Reinforced Polypropylene Resulting From Alkali-Silane Surface Treatment, proc. of $16^{\text {th }}$ Int. Conf. Compos. Struct., Porto, pp. 1-2, 2011.

[8] Kahraman, M.V., Kugu, M., Menceloglu, Y., Apohan, N. K. and Gungor, A., The novel use of organo alkoxy silane for the synthesis of organicinorganic hybrid coatings, Journal of non-crystalline Solids, 352(21-22), pp. 2143-2151, 2006. 